\title{
Colonization behaviour of arbuscular mycorrhizal fungi and phosphorus uptake pattern of mycorrhizal sensitive upland paddy using hydroponics culture
}

\author{
Swapan Kumar ${ }^{1}$, Ashim Datta ${ }^{2}$, Arunabha Pal $^{3}$ and Aniruddha Das ${ }^{1}$ \\ ${ }^{1}$ Department of Agricultural Plant Physiology, Bidhan Chandra Krishi Viswavidyalaya, Mohanpur -741252 (W.B.), \\ INDIA \\ ${ }^{2}$ Division of Soil and Crop Management, ICAR- Central Soil Salinity Research Institute, Karnal - 132001, (Haryana), \\ INDIA \\ ${ }^{3}$ Department of Soil and Water Conservation, Bidhan Chandra Krishi Viswavidyalaya, Mohanpur-741252 (W.B.), \\ INDIA \\ *Corresponding author. E-mail: swapanbckv@gmail.com
}

Received: August 26, 2014; Revised received: October 12, 2014; Accepted: January 29, 2015

\begin{abstract}
Three upland rice cultivars namely Vandana, Brown Gora and Kalinga collected from the Central Rainfed Upland Rice Research Station (CRURRS), Hazaribag, Jharkhand of the Central Rice Research Institute, are mycorrhiza sensitive genotypes. Their affinity towards mycorrhizal colonization varied. The cv. Kalinga had the highest colonization followed by Vandana and Brown Gora. Variation of arbuscular mycorrhizal fungi affinity of the rice genotypes might be due to the variable demands of phosphorus nutrition of the different genotypes. To justify these variable demands of phosphorus among these three cultivars of rice, four different doses of phosphorus (5, 10, 15 and 20 ppm) were imposed to them in a system of hydroponics. Overall, among the three cultivars, the highest uptake efficiency (34\% at 30 days, $57 \%$ at 45 days, $68 \%$ at 60 days and $70 \%$ at 75 days interval) throughout the growth period was noticed in the cv. Brown Gora, followed by Kalinga and Vandana. The physiological demands of phosphorus of these cultivars were finally estimated as the contribution of uptake phosphorus to the total dry matter production of the plants with respect to available phosphorus. The overall results of these estimations gave the highest value in cv. Kalinga followed by the cv. Vandana and Brown Gora. Therefore, the cultivars Brown Gora and Kalinga could be recommended for the cultivation of the vast upland rain-fed areas of the country for higher yield and increased phosphorus use efficiency which could ultimately contribute significantly to the food grain production of the country.
\end{abstract}

Keywords: Hydroponics, Mycorrhiza, Phosphorus, Upland rice

\section{INTRODUCTION}

Phosphorus (P) is one of the most important plant macronutrients that makes up about $0.2 \%$ of a plant's dry weight. It is a component of the key molecules of plant biology such as nucleic acids, phospholipids, and Adenosine triphosphate (ATP). Inorganic form of phosphorus $\left(\mathrm{P}_{\mathrm{i}}\right)$ is also involved in controlling key enzyme reactions and in the regulation of metabolic pathways. Plants cannot grow without a reliable supply of this nutrient. In many agricultural systems in which the application of $\mathrm{P}$ to the soil is necessary to ensure plant productivity, the recovery of applied $\mathrm{P}$ by crop plants in a growing season is very low, because in the soil more than $80 \%$ of the $\mathrm{P}$ becomes immobile and unavailable for plant uptake due to adsorption, precipitation, or conversion to the organic form (Holford, 1997).

The arbuscular mycorrhizal (AM) fungi are well known for their ability to improve the nutrition of plants, with phosphate being the most recognized plant nutrient supplied by these symbionts. It has been estimated that up to $80 \%$ of the $\mathrm{P}_{\mathrm{i}}$ taken up by a mycorrhizal plant can be supplied by the fungus. The ability of the AM fungi to supply phosphorus to the host plants has drawn special attention to the plant scientists. This is not only due to the fact that $30 \%$ of the world's agriculture suffers from the crisis of phosphorus deficiency but also phosphorus fertilizers are manufactured from nonrenewable resources that are increasingly becoming more costly and less available. Current estimates indicate that mined rock $\mathrm{P}_{\mathrm{i}}$ reserves could easily be depleted by the year 2060 (Vance et al., 2003).

World's most important cereal, rice is also a mycorrhizal sensitive plant. Rice crop has a serious demand of phosphorus fertilizer all over the world. Nearly 20 million hectares of the world's rice growing area are under upland cultivation. Nearly 6 million hectares land in India is under upland and rain-fed paddy cultivation (Adhya et al., 2008).

Phosphorus deficiency is a major constraint of upland rain-fed rice production. Past research suggested a 
linear relationship between grain yield and $\mathrm{P}$ uptake over a range of fertilizer $P$ applied to upland rice cultivars. However, there is lack of information on how these relationships are affected by the long-term fertilizer $\mathrm{P}$ effects, although such information is needed for developing $\mathrm{P}$ management strategies because phosphate fertilization effects last for several seasons (Sahrawat, 2008).

It is very difficult to predict the actual demand of phosphorus and its variation in nature among the different cultivars of rice and other plants (Veneklaas et al., 2012). Availability of phosphorus in the soil or also the phosphorus uptake rate by different cultivars do not always justify the actual requirement of this nutrition for the optimum growth of a particular variety or plant (Zhang et al., 2008). The reasons of variable affinity rate of these cultivars with AM fungi in terms of their phosphorus nutrition requirements, for the same cause cannot always be clearly understood.

Keeping these in view, the present research work was undertaken to study the AM fungi colonization behavior of three upland rice cultivars and their phosphorus uptake as well as uptake use efficiency pattern using hydroponics culture techniques throughout the growth period.

\section{MATERIALS AND METHODS}

Three upland paddy cultivars namely Vandana, Brown Gora and Kalinga were collected from the Central Rain-fed Upland Rice Research Station (CRURRS), Hazaribag, Jharkhand of the Central Rice Research Institute (CRRI), Indian Council of Agricultural Research (ICAR).

Mycorrhizal inoculum preparation, maintenance and multiplication: Arbuscular mycorrhizal (AM) fungal inoculum used for the experiments were obtained from the culture collection of the laboratory maintained for single species AM fungi cultures in root association of mycotrophic host plants. AM efficiency of these isolates in terms of root infection intensity and plant growth response were determined (Bhattacharya, 1999; Paul, 2002).

Trials on AM fungi colonization of rice cultivars: Rice seeds of the above three cultivars were sown in separate pots having $1 \mathrm{~kg}$ red-laterite soil with $1 \mathrm{~g}$ root based AM inoculum prepared as stated above. For each variety five replicated cultures were maintained $\left(\mathrm{M}^{+}\right)$. In another set the seeds of each cultivar were sown without the application of inoculum of AM $\left(\mathrm{M}^{-}\right)$. After 45 days of growth the roots were harvested from each pot and analyzed as stated below:

Processing and staining of root segments to assess AM fungi infection and histological details of root-AM fungi association: Roots, after harvesting, cleaning and washing, were preserved in formal acetic acid solution (FAA) for at least 7 days before staining with $0.1 \%$ Trypan Blue (Phillips and Hayman, 1970). Alkaline hydrolysis of root samples was done with $10 \% \mathrm{KOH}$ at $15 \mathrm{lbs}$ psi steam pressure for 2-5 minutes.
After washing, the roots were treated with $10 \%$ alkaline $\mathrm{H}_{2} \mathrm{O}_{2}(\mathrm{~V}: \mathrm{V})$ for 5 minutes. Washed roots were treated with $1 \mathrm{~N} \mathrm{HCl}$ for 5 minutes. $\mathrm{HCl}$ treated roots were then stained with hot $\left(55-60{ }^{\circ} \mathrm{C}\right) 0.1 \%$ Trypan Blue solution. Roots were destained and preserved in lactophenol before examination.

Assessment of root infection intensity: The slide micrometric method of root infection intensity assessment (Kormanik and Mc Graw, 1982) was followed to assess root infection intensity of experimental plants. Stained root segments of about $1 \mathrm{~cm}$ length, mounted in lactophenol were observed under microscope. Root and hyphal length was measured by ocular micrometer; number of vesicles and arbuscules were counted. Depending upon the purpose of experiment, a minimum of 10 and maximum of 50 root pieces were observed and averaged. Root infection intensity was expressed as per-cent root length colonized by AM fungi hyphae, number and intensity of arbuscule formation.

Raising rice plants in the nutrient culture system: To study the phosphorus uptake pattern of the three cultivars of paddy, direct seedlings were raised in hydroponics culture system in Single plant culture devices as described by Das and Majhi (2009) especially for growing rice.

Single plant culture system: The system was developed using small buckets following the Static Aerated Technique (SAT) as described by Rahaman (1997). Each bucket contained only one plant. Size of the bucket was 20.5 $\mathrm{cm}$ height, $21 \mathrm{~cm}$ diameter with a capacity of 4 liter water. At the upper surface of the bucket firstly a plastic net basket ( $6 \mathrm{~cm}$ height) was adjusted and then the top was covered with a piece of thermocol, cut as per the size of the perimeter of the upper part of the bucket. The seedlings were first sown in the central hole of the net basket. Three holes were made on this cover sheet, one for the insertion of aeration pipes into the container, another for pouring of nutrient solution and the last one at the central position to hold the plant (Plate 1).

Preparation of stock solution for nutrient culture: The nutrient solution for rice culture was prepared following Yoshida et al., (1976). The basic stock solutions and the final concentration of different nutrients were prepared as given in Table 1. The stock solutions for macro elements were prepared separately using distilled water, kept in reagent bottles and stored in a refrigerator. In case of micro elements, required quantity of all the elements along with citric acid were dissolved in 1 litre of distilled water. After mixing appropriate quantity of stock nutrients, the final volume of nutrient solution was made up by adding distilled water.

Experimental design: Each of the upland paddy cultivar was grown in four different doses of phosphorus in the applied nutrient solution as stated above. The doses of phosphorus were as follows: $5 \mathrm{ppm}, 10 \mathrm{ppm}, 15 \mathrm{ppm}$ and $20 \mathrm{ppm}$. Each dose was considered as the individual treatment for each cultivar for this experiment.

Adjustment of pH and EC of the culture solution: 
In all of the above treatments the $\mathrm{pH}$ was adjusted at 5.0 with a $\mathrm{pH}$ meter. After every 2 days interval the $\mathrm{pH}$ of the nutrient solution was checked and further adjusted if found necessary. In general the EC of the fresh solution was adjusted within the range of 1.6 $1.62 \mathrm{mS} / \mathrm{cm}$. The nutrient solution was changed once in a week at early stages and twice in a week from active tillering stage until flowering.

Measurement of Phosphorus of the nutrient solution: Phosphorus content of the nutrient solutions was measured by the Stannous chloride method (Anon, 1995).

Estimation of total phosphorus uptake by the plants: In a particular time of the growth period of the plants, from the required quantity of nutrient in a particular treatment, the total phosphorus applied was estimated. From the remaining nutrient solution of the treatment at the end of that growth period, the residual phosphorus was also measured. The subtraction of the later from the former would give the estimation of total phosphorus uptake in the treatment at that particular growth period. Total phosphorus uptake by each treatment was measured after every seven days intervals of growth of all the three cultivars of upland paddy.

Estimation of phosphorus uptake efficiency: The phosphorus uptake efficiency at a certain period of growth of the plant was estimated from the following formula (Panse and Sukhatme, 1985):

Phosphorus uptake efficiency $(\%)=$ Total phosphorus uptake by the plant during certain period of growth / Total phosphorus applied to the plant during that period of growth $\times 100$

\section{RESULTS AND DISCUSSION}

Mycorrhizal colonization in rice cultivars: Three upland rain-fed rice cultivars namely, Vandana, Brown Gora and Kalinga were tested for their colonization affinity to AM fungi. After 45 days of inoculation with mycorrhizal cultures, each cultivar was tested to study their nature of infestation by AM. The percent infestation of the cultivars is shown in Table 2.

It appears from Table 2 that the percent infestation in the inoculated $\left(\mathrm{M}^{+}\right)$cultivars Vandana, Brown Gora and Kalinga was 45.5, 39.2, and 55.2\%, respectively. The rate of infestation in all the treatments was higher than the control plants where no mycorrhizal inoculation was given. From this experiment, it could be overall predicted that the cv. Kalinga had highest affinity for mycorrhizal colonization in their roots among these three cultivars (Plate 2). Between the other two cultivars Vandana showed more colonization affinity with mycorrhiza than the cv. Brown Gora. Rain-fed upland paddy cultivars are normally more prone to AM fungi than flooded rice, which were also observed earlier by several investigators (Gangopadhyay and Das, 1982; Wangiyana et al., 2006).

It was also found in earlier reports that the response of the upland rice plants to AM colonization widely varied among the cultivars or genotypes (Dhillon, 1992; Rana et al., 2002). The three genotypes of rice, collected from the Central Rainfed Upland Rice Research Station (CRURRS) Hazaribag, Jharkhand of the Central Rice Research Institute (CRRI), ICAR, for the study of the present investigation were the indigenous upland rain-fed rice cultivars of the Eastern India and were prone to AM fungi colonization. The variation of their nature of colonization with AM fungi has been very distinct in the result of the present investigation as stated above. The more affinity of a genotype of a plant species to AM fungi and the extent of colonization might be related to the inherent demand of phosphorus nutrition of that genotype (Harrison, 2005; Oldroyd et al., 2005). This is because of the fact that the AM fungi are well known for their ability to improve the phosphorus nutrient supply to the plant to meet their nutritional demand (Marschner and Dell, 1994).

Phosphorus uptake pattern of the rice cultivars: The nature of phosphorus uptake of the three cultivars of rice at 7 days intervals is shown in Table 3. The uptake of phosphorus was measured from the hydroponics culture system where the amount of phosphorus given in the solution and the residual phosphorus in the solution after every seven days of plant growth were estimated. In general, it was observed that the rate of phosphorus uptake by the plants increased from 14 days growth stage up to 42 days growth period in all the treatments. After this growth stage the rate of uptake gradually declined and in some treatments reached to a plateau at 60-65 days age. The uptake pattern of phosphorus was not same among the three cultivars of upland rice studied in this investigation. Also this uptake pattern varied within a variety among different doses of phosphorus applied.

At all the days' interval, there was significant $(\mathrm{p}<0.05)$ uptake of phosphorus by all the cultivars (Table 3). The cv. Vandana and Kalinga showed similar trend than Brown Gora. At 14 days interval, the uptake of $\mathrm{P}$ was statistically at par for all the varieties. But after that Brown Gora reported lower uptake (4.21 mg plant ${ }^{-1}$ ) at 21 days after planting whereas other two cultivars showed significant $(\mathrm{p}<0.05)$ higher $\mathrm{P}$ uptake upto 42 days interval. Cultivar Brown Gora showed significant $(p<0.05)$ higher uptake from 28 days interval upto 42 days afterwards the uptake was decreased but still higher than the other two cultivars. Highest decrease in $\mathrm{P}$ uptake was observed at 70 days interval. The highest increase in $\mathrm{P}$ uptake was observed at 28 days interval for Brown Gora cultivar and it was continued upto 35 days interval. At 35, 42 and 49 days interval there was similar uptake pattern in case of Brown Gora cultivar. After 42 days interval, there was decrease in $\mathrm{P}$ uptake for all the cultivars studied (Table 3 ).

In all the concentration levels, except at 14 days interval there was significant $(\mathrm{p}<0.05)$ uptake of $\mathrm{P}$ at all the day's interval. At 5 and $10 \mathrm{ppm}$ concentration of $\mathrm{P}$, upto 42 days interval there was significant $(\mathrm{p}<0.05)$ 
Table 1. Composition of nutrient solution used for the experiments.

\begin{tabular}{lcc}
\hline Reagents & Stock solution (gm/liter) & $\begin{array}{c}\text { Final solution } \\
\text { (m to make 1 liter) }\end{array}$ \\
\hline $\mathrm{NH}_{4} \mathrm{NO}_{3}$ & 91.4 & 1.25 \\
$\mathrm{NaH}_{2} \mathrm{PO}_{4}, \mathrm{H}_{2} \mathrm{O}$ & 40.3 & 1.25 \\
$\mathrm{~K}_{2} \mathrm{SO}_{4}$ & 71.4 & 1.25 \\
$\mathrm{CaCl}_{2}$ & 88.6 & 1.25 \\
$\mathrm{MgSO}_{4}, 7 \mathrm{H}_{2} \mathrm{O}$ & 324.0 & 1.25 \\
$\mathrm{MnCl}_{2}, 4 \mathrm{H}_{2} \mathrm{O}$ & 1.500 & \\
$\left(\mathrm{NH}_{4}\right)_{6} \cdot \mathrm{MO}_{7} \mathrm{O}_{24} \cdot 4 \mathrm{H}_{2} \mathrm{O}$ & 0.074 \\
$\mathrm{H}_{3} \mathrm{BO}_{3}$ & 0.930 \\
$\mathrm{ZnSO}_{4}, 7 \mathrm{H}_{2} \mathrm{O}$ & 0.035 \\
$\mathrm{CuSO}_{4}, 5 \mathrm{H}_{2} \mathrm{O}$ & 0.031 \\
$\mathrm{FeCl}_{3}, 5 \mathrm{H}_{2} \mathrm{O}$ & 7.700 \\
$\mathrm{Citric} \mathrm{acid}^{2}$ & 11.900 \\
\hline $\mathrm{pH}:$ & & 1 liter \\
\hline
\end{tabular}

Table 2. Mycorrhizal colonization in rice cultivars with inoculums $\left(\mathrm{M}^{+}\right)$and control $\left(\mathrm{M}^{-}\right)$.

\begin{tabular}{lcc}
\hline Rice cultivars & $\mathbf{M}^{+}(\boldsymbol{\%})$ & $\mathbf{M}^{-}(\boldsymbol{\%})$ \\
\hline Vandana & 45.5 & 15.4 \\
Brown Gora & 39.2 & 10.2 \\
Kalinga & 55.2 & 8.7 \\
\hline
\end{tabular}

increase in $\mathrm{P}$ uptake and after that decrease in uptake was observed. Whereas at 15 and $20 \mathrm{ppm} \mathrm{P}$ concentration, at 21 days interval uptake was decreased and then increased upto 42 days interval. At 56 days interval, again increase in $\mathrm{P}$ uptake was observed at $20 \mathrm{ppm}$ concentration of P. At 63 days interval, increase $\mathrm{P}$ uptake was reported at $15 \mathrm{ppm}$ concentration (Table 3).

The interaction effect of cultivar and phosphorus concentration was found significant $(p<0.05)$ with respect to $\mathrm{P}$ uptake in all the days' interval except at 14 days. In the upland cultivar cv. Vandana, at the initial stage of growth, up to 35 days after planting, phosphorus uptake in the plants was the highest in the treatment of $10 \mathrm{ppm}$ available phosphorus in the nutrient solution. Up to this stage of growth of this cultivar, the higher doses of available phosphorus in the nutrient solution i.e. $15 \mathrm{ppm}$ and $20 \mathrm{ppm}$ could not increase the phosphorus uptake by the plants more than the treatment of $10 \mathrm{ppm}$. After 35 days of growth, the phosphorus uptake by the plants sharply increased in the highest dose of treatment (20 ppm) and that exceeded all the other treatments. At $15 \mathrm{ppm}$ application dose, however, the phosphorus uptake was found to be declined further up to 60 days age of the plants and after that it suddenly increased and exceeded the lower doses of treatments. At the lowest dose of treatment ( $5 \mathrm{ppm})$ the phosphorus uptake by the plants was the least among all the treatments throughout the growth period (Table 3).

In the upland cultivar cv. Brown Gora, there was a distinct differentiation of the treatments as shown in Table 3. Here the phosphorus uptake by the plants increased sharply as the doses of applications increased and that phenomenon was observed throughout the growth period of this cultivar. From the 35 to 40 days after planting, the phosphorus uptake of the plants was almost steady. The uptake of phosphorus was higher in the plants as per the higher order of available phosphorus doses in the nutrition solutions. So at the $20 \mathrm{ppm}$ dose, the phosphorus uptake was the highest following the doses of $15 \mathrm{ppm}, 10 \mathrm{ppm}$ and $5 \mathrm{ppm}$. In the treatments of lower doses of phosphorus applications (5, 10 and $15 \mathrm{ppm})$, there were little trend of decline of phosphorus uptake by the plants at the advanced stages of growth. However, at the highest dose this phenomenon was not observed (Table 3 ).

In the cv. Kalinga, at the initial stage of growth, up to 30-35 days after planting, phosphorus uptake by the plants at the two upper doses of treatments (15 and 20 ppm) was almost same and distinctly higher than the two other lower doses of treatments (5 and $10 \mathrm{ppm}$ ). After 35-40 days of growth, the phosphorus uptake of the plants was higher as per the higher order of available phosphorus doses in the nutrition solutions. So at 20 ppm dose, the phosphorus uptake was the highest following the doses of 15, 10 and $5 \mathrm{ppm}$. The phosphorus uptake by the plants sharply increased at the highest dose of treatment $(20 \mathrm{ppm})$ and that exceeded all the other treatments. At 15 ppm dose, however, the phosphorus 
Table 3. Quantity of Phosphorus (mg plant ${ }^{-1}$ ) uptake of the three rice cultivars at different doses of applied phosphorus.

\begin{tabular}{lccccccccc}
\hline $\begin{array}{l}\text { Treatments/Days } \\
\text { Interval }\end{array}$ & $\mathbf{1 4}$ & $\mathbf{2 1}$ & $\mathbf{2 8}$ & $\mathbf{3 5}$ & $\mathbf{4 2}$ & $\mathbf{4 9}$ & $\mathbf{5 6}$ & $\mathbf{6 3}$ & $\mathbf{7 0}$ \\
\hline V1 (Vandana) & 9.38 & 10.04 & 21.82 & 51.26 & 61.04 & 47.78 & 50.79 & 55.08 & 25.48 \\
V2 (Brown Gora) & 10.59 & 4.21 & 31.69 & 69.02 & 69.66 & 68.37 & 64.53 & 62.46 & 30.21 \\
V3 (Kalinga) & 9.83 & 11.39 & 15.66 & 53.28 & 66.04 & 57.55 & 52.11 & 45.90 & 23.27 \\
S.Em( \pm ) & 0.629 & 0.11 & 0.18 & 0.22 & 0.13 & 0.14 & 0.10 & 0.13 & 0.18 \\
CD(P=0.05) & 1.844 & 0.33 & 0.52 & 0.63 & 0.37 & 0.40 & 0.28 & 0.37 & 0.53 \\
C1 (5ppm) & 5.64 & 7.52 & 12.21 & 30.06 & 32.77 & 29.76 & 26.75 & 18.44 & 12.00 \\
C2 $(10 p p m)$ & 8.66 & 11.75 & 25.70 & 54.21 & 61.90 & 57.45 & 55.45 & 50.54 & 22.38 \\
C3 $(15 p p m)$ & 7.90 & 6.09 & 27.19 & 67.37 & 73.92 & 62.63 & 50.70 & 62.41 & 30.58 \\
C4 (20ppm) & 17.53 & 8.81 & 27.13 & 79.76 & 93.73 & 81.75 & 90.34 & 86.51 & 40.32 \\
S.Em( \pm$)$ & 0.726 & 0.13 & 0.20 & 0.25 & 0.14 & 0.16 & 0.11 & 0.15 & 0.21 \\
CD(P=0.05) & NS & 0.38 & 0.60 & 0.73 & 0.42 & 0.47 & 0.33 & 0.43 & 0.62 \\
V1C1 & 4.33 & 7.40 & 12.31 & 25.78 & 30.80 & 28.35 & 26.67 & 18.44 & 12.05 \\
V1C2 & 9.73 & 18.24 & 35.36 & 65.88 & 72.01 & 63.54 & 55.95 & 50.34 & 16.95 \\
V1C3 & 6.20 & 4.77 & 19.59 & 53.83 & 65.42 & 30.10 & 41.18 & 72.01 & 31.03 \\
V1C4 & 17.25 & 9.73 & 20.01 & 59.56 & 75.94 & 69.11 & 79.35 & 79.51 & 41.89 \\
V2C1 & 5.61 & 1.44 & 18.00 & 31.20 & 33.56 & 30.21 & 27.48 & 18.44 & 12.04 \\
V2C2 & 8.26 & 5.65 & 34.21 & 67.83 & 64.16 & 63.00 & 55.64 & 50.64 & 25.30 \\
V2C3 & 10.05 & 2.45 & 36.06 & 79.56 & 87.15 & 86.73 & 77.10 & 80.36 & 37.08 \\
V2C4 & 18.42 & 7.31 & 38.49 & 97.48 & 93.76 & 93.55 & 97.90 & 100.40 & 46.43 \\
V3C1 & 6.97 & 13.73 & 6.31 & 33.21 & 33.96 & 30.73 & 26.09 & 18.44 & 11.91 \\
V3C2 & 7.98 & 11.37 & 7.52 & 28.93 & 49.53 & 45.81 & 54.77 & 50.64 & 24.89 \\
V3C3 & 7.46 & 11.05 & 25.91 & 68.73 & 69.19 & 71.05 & 33.83 & 34.87 & 23.63 \\
V3C4 & 16.92 & 9.40 & 22.88 & 82.23 & 111.48 & 82.60 & 93.76 & 79.63 & 32.63 \\
S.Em( \pm$)$ & 1.257 & 0.23 & 0.35 & 0.43 & 0.25 & 0.28 & 0.19 & 0.26 & 0.36 \\
CD(P=0.05) & NS & 0.67 & 1.04 & 1.26 & 0.73 & 0.81 & 0.57 & 0.75 & 1.07 \\
\hline Whe V & & & & & & & &
\end{tabular}

Where $\mathrm{V}$ indicates cultivar and $\mathrm{C}$ indicates $\mathrm{P}$ concentration, V1: Vandana; V2: Brown Gora; V3: Kalinga; and C1: 5ppm; C2: 10 ppm; C3: 15 ppm; C4: 20 ppm.

uptake was found to be declined further at 49 days age of the plants and at the more advanced stage of growth, the phosphorus uptake by the plants at this treatment declined more than its next lower dose of available phosphorus treatment (10 ppm). So phosphorus uptake by this cultivar at the advanced stage of growth of the plants was higher at $10 \mathrm{ppm}$ available phosphorus than that of $15 \mathrm{ppm}$ treatment. After 35 days of planting, at the lowest dose of treatment (5 ppm), phosphorus uptake by the plants was the least among all the treatments throughout the remaining growth period (Table 3 ).

When phosphorus is applied in the soil in the form of fertilizer, in many agricultural systems the recovery of applied $\mathrm{P}$ by crop plants in a growing season becomes very low, because more than $80 \%$ of the $\mathrm{P}$ becomes immobile and unavailable for plant uptake due to adsorption, precipitation, or conversion to the organic form (Holford, 1997). In the system adopted in this experiment, the chances of occurring these incidences were absolutely minimized as the entire application was made in the nutrient culture system of hydroponics. There was also no scope of loss of phosphorus from the nutrient solution in a given period of time when this estimation of phosphorus uptake by the plants was measured. In this experiment, it was observed that the uptake of phosphorus by the rice plants in different treatments varied at different growth stage that was also observed by the pioneer workers of this area (Yoshida et al. 1976). Also as observed in the present investigation, it was found earlier that the phosphorus uptake pattern of rice plants greatly varied with the varieties (Choudhury, 2000).

Phosphorus uptake efficiency pattern of the rice cultivars: In this experiment, the phosphorus uptake efficiency of the treatments was estimated from the total phosphorus applied to the plant and the percentage of phosphorus taken by the plant in a course of time of growth period. These values are not the physiological 
Table 4. Phosphorus uptake efficiency (\%) of the three rice cultivars at different doses of applied phosphorus at different day's' intervals.

\begin{tabular}{|c|c|c|c|c|}
\hline Treatment/Days Interval & 30 & 45 & 60 & 75 \\
\hline V1 (Vandana) & 26.50 & 41.95 & 48.19 & 51.72 \\
\hline V2 (Brown Gora) & 33.89 & 57.42 & 67.73 & 70.37 \\
\hline V3 (Kalinga) & 28.28 & 49.41 & 57.86 & 59.78 \\
\hline $\operatorname{S.Em}( \pm)$ & 0.11 & 0.15 & 0.13 & 0.10 \\
\hline $\mathrm{CD}(\mathrm{P}=0.05)$ & 0.31 & 0.44 & 0.37 & 0.31 \\
\hline $\mathrm{C} 1(5 \mathrm{ppm})$ & 43.59 & 70.10 & 77.92 & 80.99 \\
\hline $\mathrm{C} 2(10 \mathrm{ppm})$ & 28.92 & 43.86 & 54.32 & 59.10 \\
\hline C3 (15 ppm) & 23.35 & 43.39 & 49.69 & 47.53 \\
\hline $\mathrm{C} 4(20 \mathrm{ppm})$ & 22.36 & 41.01 & 49.77 & 54.85 \\
\hline $\operatorname{S.Em}( \pm)$ & 0.12 & 0.17 & 0.14 & 0.12 \\
\hline $\mathrm{CD}(\mathrm{P}=0.05)$ & 0.36 & 0.51 & 0.42 & 0.35 \\
\hline $\mathrm{V} 1 \mathrm{C} 1$ & 41.31 & 64.08 & 73.03 & 76.82 \\
\hline $\mathrm{V} 1 \mathrm{C} 2$ & 25.76 & 34.29 & 39.29 & 41.81 \\
\hline $\mathrm{V} 1 \mathrm{C} 3$ & 19.28 & 36.44 & 39.17 & 41.05 \\
\hline $\mathrm{V} 1 \mathrm{C} 4$ & 19.65 & 32.98 & 41.28 & 47.18 \\
\hline $\mathrm{V} 2 \mathrm{C} 1$ & 43.04 & 71.38 & 79.42 & 82.30 \\
\hline $\mathrm{V} 2 \mathrm{C} 2$ & 39.15 & 61.39 & 73.22 & 77.38 \\
\hline $\mathrm{V} 2 \mathrm{C} 3$ & 26.51 & 50.75 & 62.52 & 59.86 \\
\hline $\mathrm{V} 2 \mathrm{C} 4$ & 26.86 & 46.16 & 55.74 & 61.93 \\
\hline $\mathrm{V} 3 \mathrm{C} 1$ & 46.41 & 74.85 & 81.30 & 83.86 \\
\hline $\mathrm{V} 3 \mathrm{C} 2$ & 21.86 & 35.90 & 50.46 & 58.12 \\
\hline $\mathrm{V} 3 \mathrm{C} 3$ & 24.25 & 42.99 & 47.37 & 41.68 \\
\hline $\mathrm{V} 3 \mathrm{C} 4$ & 20.58 & 43.89 & 52.29 & 55.44 \\
\hline $\operatorname{S.Em}( \pm)$ & 0.21 & 0.30 & 0.25 & 0.21 \\
\hline $\mathrm{CD}(\mathrm{P}=0.05)$ & 0.62 & 0.88 & 0.73 & 0.61 \\
\hline
\end{tabular}

Where V indicates variety and C indicates P concentration, V1: Vandana; V2: Brown Gora; V3: Kalinga; C1: 5 ppm; C2: 10 ppm; C3:15 ppm; C4: 20 ppm

efficiency of the phosphorus utilization of the plants which was usually termed as Phosphorus use efficiency but signified the capacities of the plants to uptake phosphorus from variable doses of availability of phosphorus in the nutrient solution.

At all the days' interval, all the cultivars showed significant $(\mathrm{p}<0.05) \mathrm{P}$ uptake efficiency. With increase in day's interval, $\mathrm{P}$ uptake efficiency increased significantly $(\mathrm{p}<0.05)$. But the cultivar Brown Gora showed highest $P$ uptake efficiency at all the day's interval than Vandana and Kalinga whereas cv. Vandana and Kalinga reported similar P uptake efficiency (Table 4). At all the phosphorus concentration levels, there was significant $(\mathrm{p}<0.05)$ increase in P uptake efficiency at all the day's interval. Highest P uptake efficiency was observed at $5 \mathrm{ppm}$ concentration level at all the interval days. At 15 and $20 \mathrm{ppm}$ concentration, the $\mathrm{P}$ uptake efficiency trend was similar. The interaction effect of cultivar and phosphorus concentration with respect to $\mathrm{P}$ uptake efficiency was significant $(\mathrm{p}<0.05)$ in all the days' interval (Table 4). It could generally be understood from the overall data of this estimation that the per cent uptake of phosphorus by all the cultivars decreased as the quantity of available phosphorus in the nutrient solution increased. At the lowest availability of phosphorus in the nutrient solution $(5 \mathrm{ppm})$ all the cultivars showed their highest efficiency of phosphorus uptake at all the stages of growth starting from 30 days to 75 days after planting (Table 4). However, at the higher doses of phosphorus availability the responses of the cultivars to uptake phosphorus varied significantly. This variation was also pronounced at different ages of the plants.

It was observed from the data that at all the stages of growth, the per cent phosphorus uptake from the available phosphorus were the highest at the lowest dose of application $(5 \mathrm{ppm})$ for all the three cultivars. At this dose of application, the highest efficiency was always shown by the cultivar Kalinga followed by Brown 


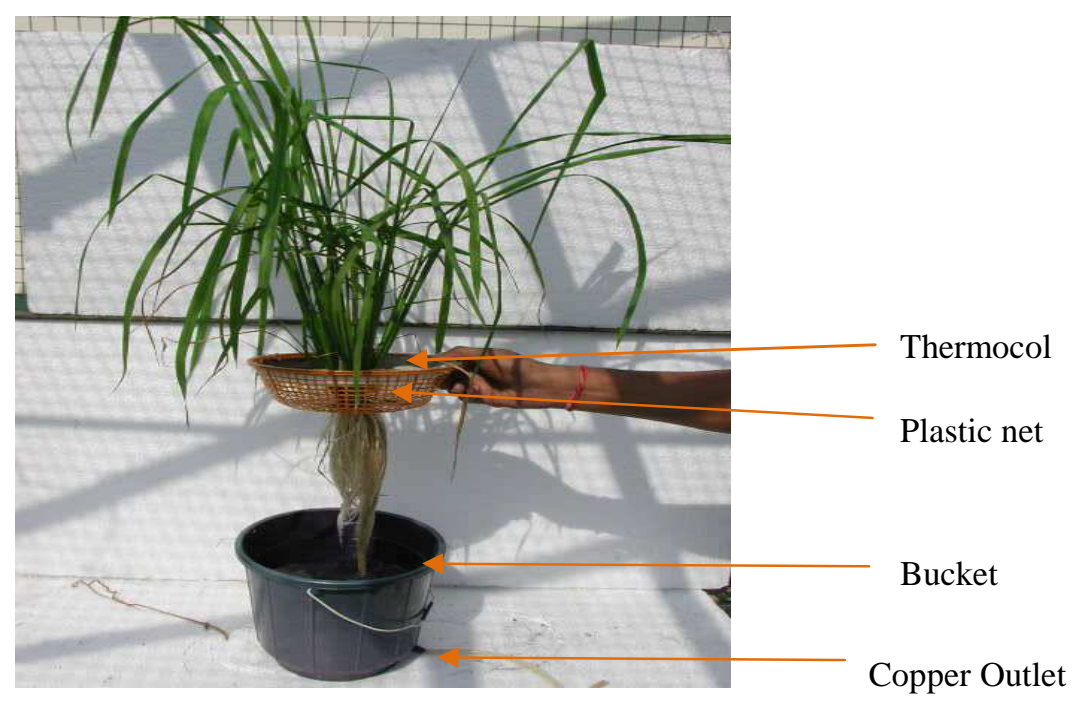

Plate 1: Single Plant Culture System of Hydroponics modified for Rice cultivation.

Gora and Vandana. However, this scenario was changed at the higher doses of phosphorus application. At all the stages of growth, starting from 30 days to 75 days ages of the plants, the highest per cent of phosphorus uptake from all of those available phosphorus treatments in the solution $(10,15$ and $20 \mathrm{ppm})$ were observed in the cultivar Brown Gora (Table 4).

In most of the cases the next highest efficiency was shown by the cultivar Kalinga and the least efficiency was shown by the cultivar Vandana. However, some exceptions were also there at different stages of growth of the plants of these two cultivars. At 30 days age of the plants, the per cent phosphorus uptake by Vandana was higher than Kalinga at the $10 \mathrm{ppm}$ phosphorus availability in the solution (Table 4, Plate 3). But in the treatments of 15 and 20 ppm doses, per cent phosphorus uptake of cv. Kalinga exceeded that of Vandana (Table 4).

Similarly at the 75 days age of the plant, at the dose of 15 ppm availability of phosphorus, the uptake efficiency of these two cultivars was almost same. However, at this age, in the next higher dose (20 ppm), per cent phosphorus uptake by the plants of cv. Kalinga distinctly exceeded that of cv. Vandana (Table 4).

From the observations as stated above, it could be clearly revealed that the three cultivars of upland rice had differential capacities to uptake phosphorus at different levels of availability of phosphorus. At the lowest level of applied phosphorus, all the cultivars showed their maximum efficiency to uptake phosphorus from the nutrient solution. At the higher level of availability of this nutrient, the rate of increase of the uptake significantly $(\mathrm{p}<0.05)$ varied among the cultivars. The cv. Brown Gora showed the highest capacity of uptake whereas the cv. Kalinga showed the medium level and cv. Vandana had the least capacity of this nutrient uptake at the higher level of availability of phosphorus in the applied nutrient source. In soil, the phosphorus uptake efficiency always depends on the availability of phosphorus.
However, the capacity to uptake phosphorus greatly varies among the genotypes (Diamond, 1985).

\section{Conclusion}

The cv. Kalinga (55.2\%) showed the highest colonization followed by Vandana $(45.5 \%)$ and Brown Gora $(39.2 \%)$. The rate of phosphorus uptake by the plants increased from 14 days growth stage up to 42 days in all the treatments. At the lowest dose of available phosphorus the highest uptake efficiency was found in the cv. Kalinga followed by Brown Gora and Vandana. The results also indicated that the $15 \mathrm{ppm}$ availability of phosphorus in the solution was optimum for the maximum consumption and use of phosphorus nutrition for this group of upland paddy. The differences in the phosphorus use efficiencies of the three upland rice genotypes may justify their affinity level to colonize AM fungi.

\section{REFERENCES}

Adhya, T.K., Singh, O.N., Swain, P. and Ghosh, A. (2008). Rice in Eastern India: Causes for low productivity and available options. Journal of Rice Research, Vol.2, No. 1, $1-5$.

Anon. (1995). Standard methods for the examination of water and wastewater. American Public Health Association, American Water Works Association, Water Environment Federation Eaton, A.D.; Clesceri, L.S. and Greenberg, A.E. (Eds.) pp 111.

Bhattacharya, P.M. (1999). Studies on VA-mycorrhiza and other growth promoting rhizosphere microorganisms of tree plants with special reference to Bamboos. Ph.D. Thesis. Department of Plant Pathology, Bidhan Chandra Krishi Viswavidyalaya, Nadia, West Bengal, India, pp 261.

Choudhury, A.T.M.A. (2000). Adjusting N, K, Mg and Cu rates for improvement of fertilizer $\mathrm{N}$ use efficiency in rice production in Malaysia, Ph.D. Thesis, Faculty of Agriculture, University Putra Malaysia.

Das, A. and Majhi, D.S. (2009). Low cost hydroponics devices 


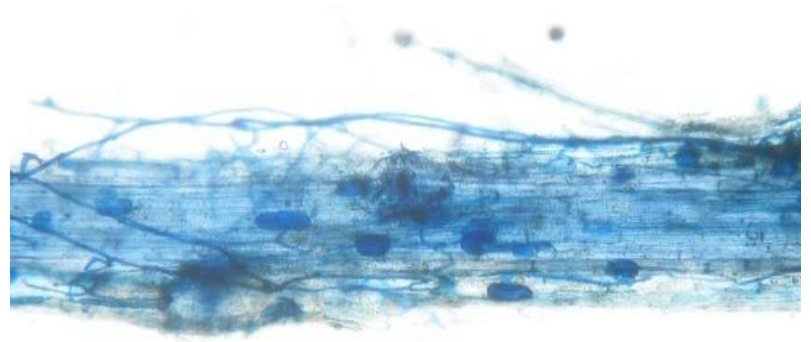

A. AMF colonization in $c v$ Vandana

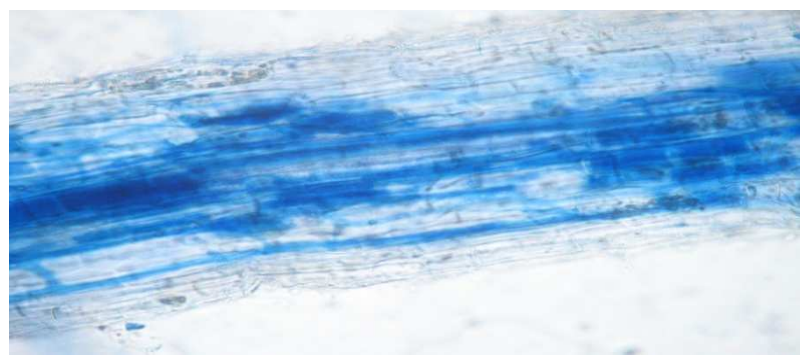

B. AMF colonization in cv.Brown Gora

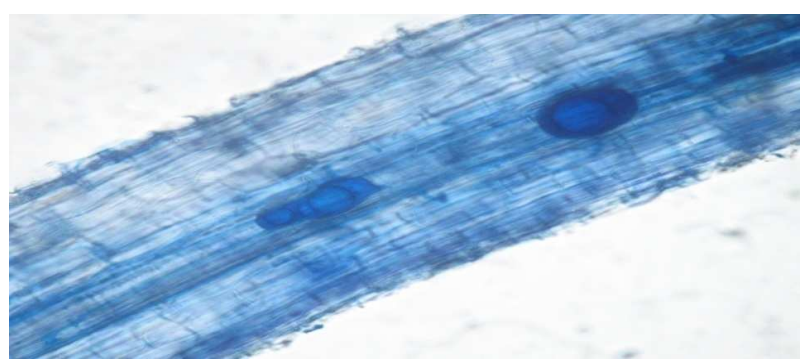

C. AMF colonization in cv Kalinga

Plate 2. AM Fungi colonization in upland rice cultivars (A. Vandana; B. Brown Gora; C. Kalinga).

and use of harvested water for vegetable and flower cultivation. Journal of Applied Horticulture, 11: 123127.

Dhillon, S.S. (1992). Host endophyte specificity of vesicular arbuscular mycorrizal colonization of Oryza sativa L. at the pretransplanted stage in low or high phosphorus soil. Soil Biology Biochemistry, 24: 405-411.

Diamond, R.B. (1985). Availability and Management of Phosphorus in Wetland Soils in Relation to Soil Characteristics. Wetland Soils: Characterization, Classifications and Utilization. Banta, S.J. (Ed.), International Rice Research Institute, Los Banos, Philippines, pp 269-283.

Gangopadhyay, S. and Das, K.M. (1982). Occurrence of vesicular mycorrhiza in India. Indian Phytopathology, 35: 83-85.

Harrison, M. (2005). Signaling on the arbuscular mycorrhizal symbiosis. Annual Review of Microbiology, 59: 19 - 42.

Holford, I.C.R. (1997). Soil phosphorus: its measurement and its uptake by plants. Australian Journal of Soil
Research, 35: 227-239.

Kormanik, P.P. and McGraw, A.C. (1982). Quantification of vesicular-arbuscular mycorrhizae in plant roots. In: Methods and Principles of Mycorrhizal Research, ed. Schenck, NC, Amer. Phytopathol. Soc., Minnesota, USA, pp 37-46.

Marschner, H. and Dell, B. (1994). Nutrient uptake in mycorrhizal symbiosis. Plant and Soil, 159: 89-102.

Oldroyd, G.E.D., Harrison M.J. and Udvardi, M. (2005). Peace talks and trade deals. Keys to long-term harmony in legume microbe symbioses. Plant Physiology, 137: 1205-121.

Panse, V.G. and Sukhatme, P.V. (1985). Statistical Methods for Agricultural Workers, ICAR, New Delhi, pp 359.

Paul, A.K. (2002). Studies on mycorrhizal and micropropagation technology of Citrus spp. in relation to improvement of citriculture. Ph.D Thesis. Department of Plant Pathology, BCKV, Nadia, West Bengal, India, pp 295.

Phillips, J.M. and Hayman, D.S. (1970). Improved procedures for clearing roots and staining parasitic and vesicular arbuscular mycorrhizal fungi for rapid assessment of infection. Transactions of the British Mycological Society, 55: 157-160.

Rahaman, F.M. (1997). Hydroponics. Journal of Ngee ann Polytechnic (Singapor), 12: 36-48.

Rana, S.K., Maiti, D., Barnwal, M.K., Singh, R.K. and Variar, M. (2002). Effect of rice (Oryza sativa)-based intercropping systems on vesicular-arbuscular myrcorrhizal colonization, P uptake and yield. Indian Journal of Agricultural Sciences, 72(7): 400-403.

Sahrawat, K.L. (2008). Direct and residual phosphorus effects on grain yield-phosphorus uptake relationships in upland rice on an ultisol in West Africa. International-Journal -of-Plant-Production, 2(4): 281-287.

Vance, C.P., Uhde-Stone, C. and Allan, D.L. (2003). Phosphorus acquisition and use: critical adaptations by plants for securing a nonrenewable resource. New Phytologist, 157: 423-44.

Wangiyana, W., Cornish, P.S. and Morris, E.C. (2006). Arbuscular mycorrhizal fungi dynamics in contrasting cropping systems on vertisol and regosol soils of Lombok, Indonesia. Experimental Agriculture, 42(4): 427-439.

Yoshida, S., Douglas, A.F., Cook, J.H. and Gomez, K.A. (1976). In laboratory manual for physiological studies of rice ( $3^{\text {rd }}$ Ed.). IRRI, Los Banos, Lagune, Philippines. pp83.

Zhang-YaJie, Yang-Jian, C. and Du-Bin. (2008). Effects of cultivation methods on the absorption and use efficiency of phosphorus in upland rice and paddy rice. Acta -Agronomica-Sinica, 34(1): 126-132.

Veneklaas, E.J., Lambers, H., Bragg, J., Finnegan, P.M., Lovelock, C.E., Plaxton, W.C., Price, C.A., Scheible, W., Shane, M.W., White, P.J. and Raven, J.A. (2012). Opportunities for improving phosphorus-use efficiency in crop plants. New Phytologist, 195: 306-320. 